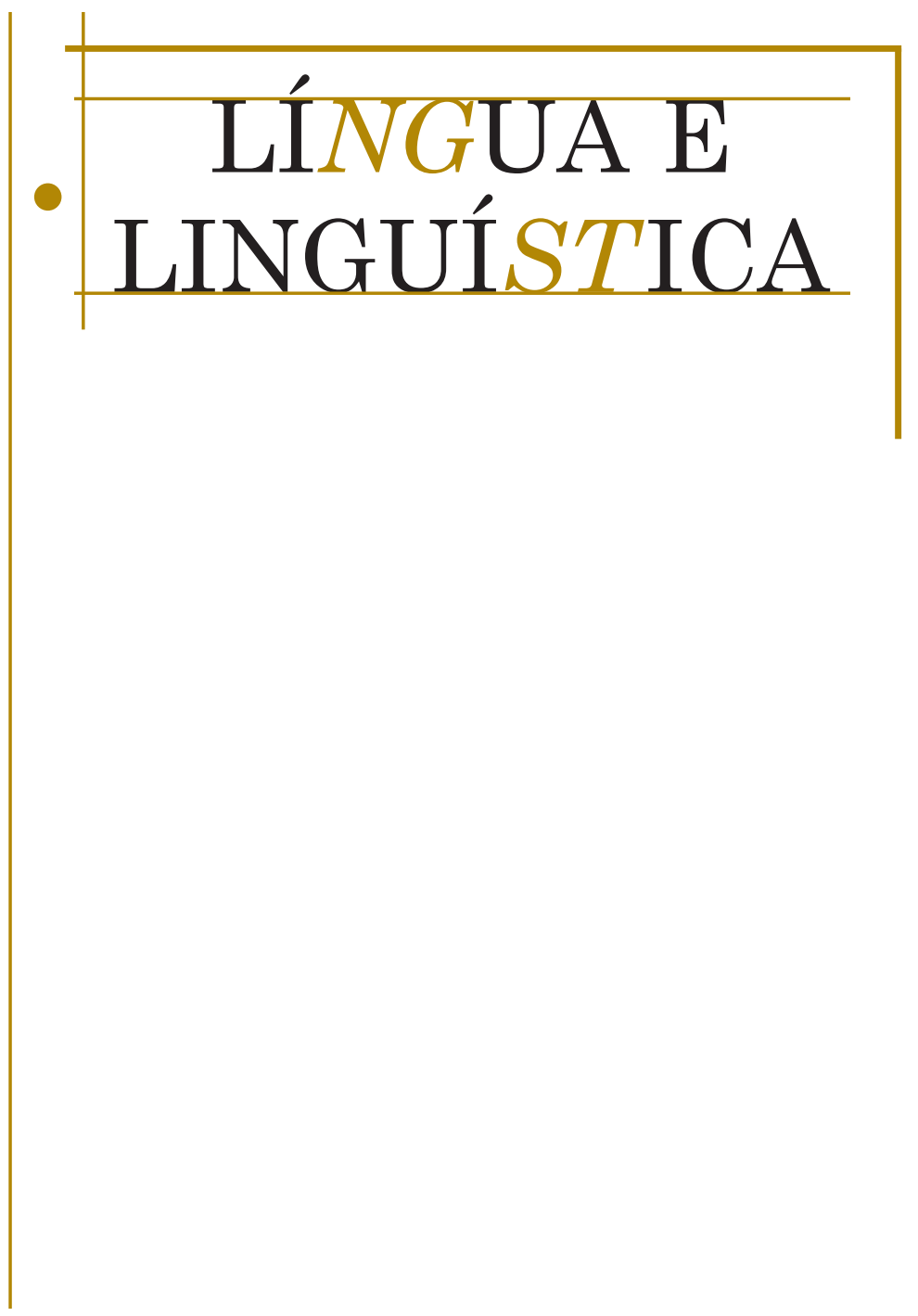




\section{MANIPULAÇÃO, MODALIZAÇÕES E O FAZER CRER EM "VENHA VER O PÔR DO SOL"}

Sonia Merith-Claras*

Resumo: Neste trabalho, à luz da Semiótica, nosso objetivo é apresentar um estudo do conto "Venha ver o pôr do sol", de Lygia Fagundes Telles, evidenciando os sentidos imanentes a partir das escolhas de um enunciador. Fazem parte da análise as estratégias de manipulação entre os sujeitos da narrativa e entre enunciador/enunciatário, bem como a organização dos percursos figurativos e as temáticas subjacentes. É possível pensar, por meio da análise realizada, uma forma de se trabalhar o conto no contexto escolar.

Palavras-chave: Leitura. Manipulação. Fazer crer.

\section{INTRODUÇÃO ${ }^{1}$}

"O conto "Venha ver o pôr do sol" dá nome ao livro que reúne outros contos de Lygia Fagundes Telles (2007): "O noivo", "Natal na barca", "As formigas", "O jardim selvagem", "Biruta", "Antes do baile verde" e "O menino". Nosso interesse pelo conto em questão se deu, principalmente, por acreditarmos que sua forma de organização, bem como a temática abordada, é de interesse do público adolescente. Nesse sentido, há a possibilidade de desenvolver o estudo aqui apresentado com os jovens estudantes no contexto escolar, como forma de incentivar a leitura do texto literário, como sugerem os Parâmetros Curriculares Nacionais (BRASIL, 1998) e a Base Nacional Comum Curricular (BRASIL, 2017).

Considerando o fazer crer presente na obra, percorremos, num primeiro momento, as relações persuasivas entre os sujeitos da narrativa e seus objetos-valores, bem como o desenrolar das unidades sintáxicas, que envolvem desti-

\footnotetext{
Universidade Estadual do Centro-Oeste (Unicentro), Guarapuava, PR, Brasil. E-mail: soniaclame@gmail.com

1 Este trabalho foi apresentado, em forma de comunicação oral, no VI Simpósio Mundial de Estudos da Língua Portuguesa em Santarém, Portugal, em 2017.
} 
nador e destinatário. É no viés desse nível, o narrativo, que abordaremos as modalidades veridictórias que tratam do SER e PARECER e as modalidades epistêmicas que envolvem o CRER.

Por fim, enfatizaremos as escolhas do enunciador, num jogo de fazer CRER entre enunciador e enunciatário. Por meio de um exercício analítico, então, respaldados na teoria semiótica greimasiana, percorreremos alguns percursos de leitura, com base em escolhas, marcas deixadas, ou não, de um enunciador no enunciado, que recobrem percursos figurativos e temáticos. Antes da análise, porém, retomamos os pressupostos teórico-metodológicos da semiótica greimasiana, discorrendo, mais detalhadamente, sobre os niveis narrativo e discursivo do percurso gerativo do sentido.

\section{SEMIÓtICA GREIMASIANA: PRESSUPOSTOS TEÓRICOS}

De acordo com Greimas e Courtés (2013, p. 232), todo objeto semiótico pode ser definido segundo o modo de sua produção, na perspectiva da geração, assim, "os componentes que intervêm nesse processo se articulam um com os outros de acordo com um 'percurso' que vai do mais simples ao mais complexo, do mais abstrato ao mais complexo". Segundo a proposta greimasiana, no que tange ao plano do conteúdo, os sentidos podem ser concebidos, metodologicamente, sob a forma de um percurso gerativo, o qual compreende três níveis, ou etapas, em que cada um deles pode ser descrito e explicado por uma gramática autônoma, apesar de o sentido de um texto, por exemplo, depender da relação desses níveis. O nível mais abstrato e simples é denominado nível fundamental, quando a significação pode ser estudada baseada em uma oposição semântica mínima. No segundo nível do percurso, o narrativo, a narrativa é organizada do ponto de vista de um sujeito. Neste nivel, os elementos das oposições semânticas, das estruturas fundamentais, "são assumidos como valores por um sujeito e circulam entre sujeitos, graças à ação de sujeitos” (BARROS, 2005, p. 11). Não se trata, portanto, de afirmar ou negar conteúdos, mas de transformar, pela ação de um sujeito, os estados. No último nivel, o discursivo, mais superficial e complexo, a narrativa é assumida pelo sujeito da enunciação. "As estruturas discursivas devem ser examinadas do ponto de vista das relações que se instauram entre a instância da enunciação, responsável pela produção e pela comunicação do discurso, e o texto-enunciado" (BARROS, 2005, p. 11).

É no nível narrativo, interesse de nosso estudo, que se estabelecem os processos de manipulação, os quais supõem uma relação entre destinador-manipulador e destinatário-manipulado, uma espécie de contrato entre essas relações sintáxicas. Há um esforço do destinador-manipulador em despertar a confiança do destinatário-manipulado, levando-o a crer, para em seguida, induzi-lo a um fazer ou não-fazer. Contudo, para que um sujeito execute um fazer, em que é preciso alterar a sua competência modal para se concretizar um processo de manipulação, e o manipulado execute um fazer, este precisa querer e/ou dever, saber ou poder. Dessas competências modais, resultam os tipos de manipulação como a provocação e a intimidação, quando o destinatário-manipulado é persuadido a um dever-fazer; ou a sedução e a tentação, quando o destinatário-manipulado é induzido a um querer-fazer.

O processo de manipulação, quando os actantes da narrativa nas funções de destinador-manipulador, destinatário-manipulado, sujeito e objeto estão 
envolvidos, só terá sucesso quando o sistema de valores for "compartilhado pelo manipulador e pelo manipulado, quando houver certa cumplicidade entre eles" (BARROS, 2005, p. 33). Portanto, a manipulação tende a ser bem-sucedida quando destinador-manipulador e destinatário-manipulado estão de acordo sobre o que é desejável ou indesejável dentro de determinado contexto cultural. Ressalte-se, nesse processo, o papel do destinatário como aquele que avalia, aceita ou refuta os valores postos em cena, realizando um fazer interpretativo do sujeito. "O fazer interpretativo é caracterizado como um fazer cognitivo que consiste em modalizar um enunciado pelo parecer e pelo ser e em estabelecer a correlação entre os dois planos, da manifestação e da imanência" (BARROS, 1995, p. 89). Ser e parecer são modalidades veridictórias que estão diretamente ligadas à imanência e à manifestação, respectivamente, e ao fazer crer - modalidades epistêmicas. Consoante Greimas e Courtés (2013), o parecer/não parecer é chamado de manifestação, enquanto o esquema do ser/ não ser, de imanência.

Dessa forma, os enunciados modalizados veridictoriamente podem ser ditos como verdadeiros, parece e é; falsos, não parece e não é; mentirosos, parece, mas não é; ou secretos, não parece, mas é. A interpretação realizada pelo destinatário/fazer interpretativo (modalidades epistêmicas) consistirá em modalizar a proposta do destinador, com seu fazer persuasivo.

De acordo com Greimas e Courtés (2013, p. 172), as modalidades epistêmicas referem-se à competência modal do enunciatário e/ou destinador.

As modalidades epistêmicas dizem respeito à competência do enunciatário (ou, no caso do discurso narrativo, do Destinador final) que, em seguida ao seu fazer interpretativo, "toma a cargo", assume (ou sanciona) as posições cognitivas formuladas pelo enunciador (ou submetidas pelo Sujeito). Na medida em que no interior do contrato enunciativo (implicito ou explícito) o enunciador exerce um fazer interpretativo por um juízo epistêmico (isto é, por um crer) que ele emite sobre os enunciados de estado que the são submetidos.

Todavia, é no nível discursivo, também abordado neste texto, que os valores do nível narrativo são disseminados no discurso de modo abstrato, sob a forma de percursos temáticos, os quais são investidos e concretizados em percursos figurativos. O nível discursivo, então, será veiculado por um ou vários planos da expressão, produzindo textos que são, na verdade, a manifestação do discurso. É neste nível que a organização da narrativa é temporalizada, espacializada e actorializada ou, ainda, quando a narrativa é assumida pelo sujeito da enunciação, que opera num tempo, agora, e num espaço, aqui. Com base nas contribuições de Benveniste (1989), para quem a enunciação é a colocação em funcionamento da lingua por um ato individual do falante, Greimas e Courtés (2013, p. 166) defendem que a enunciação é "uma instância linguística, logicamente pressuposta pela própria existência do enunciado (que dela contém traços e marcas)". Sendo assim, é no enunciado que podemos encontrar elementos que remetem à instância da enunciação. De acordo com a proposta greimasiana, um dos mecanismos de instauração de pessoa, tempo e espaço no enunciado é a debreagem - enunciva e enunciativa. Na debreagem enunciva, o enunciador provoca um efeito de distanciamento do seu lugar enunciativo, instaurando, portanto, um discurso em terceira pessoa, ele, no tempo do então, no espaço do lá, que não os da enunciação. Em contrapartida, na debreagem enunciativa, o 
enunciador produz um efeito de aproximação de sua própria instância, na medida em que se manifesta em primeira pessoa, eu, no espaço do aqui e no tempo do agora. Em síntese, conforme destaca Fiorin (2008), há textos enunciativos, ou ainda, enunciação enunciada, quando o conjunto de marcas, no enunciado identificável, remete à instância da enunciação; e textos enuncivos, quando no enunciado a sequência enunciada é desprovida de marcas da enunciação. Tanto a debreagem enunciva quanto a enunciativa, as quais produzem, respectivamente, efeitos de objetividade e subjetividade, são estratégias utilizadas pelo enunciador no intuito de que as coisas, os ditos pareçam verdadeiros ao seu enunciatário.

Desta forma, segundo Barros (2005), enunciador e enunciatário são desdobramentos do sujeito da enunciação e, desta forma, cumprem os papéis de destinador e destinatário do discurso. No jogo de persuasão, o enunciador assume o papel de destinador-manipulador e, por meio de valores do discurso, procura manipular o enunciatário, no papel de destinatário, a crer e a fazer. "Tanto a persuasão do enunciador quanto a interpretação do enunciatário se realizam no e pelo discurso" (BARROS, 2005, p. 62). O enunciador, então, constrói no discurso um dispositivo veridictório, espalhando marcas e pistas que deverão ser lidas e interpretadas pelo enunciatário. Faz parte desse jogo persuasivo as crenças, valores, visão de mundo que envolvem enunciador e enunciatário.

Em suma, as comunicações objetivam firmar um contrato fiduciário, que é a principal garantia para se estabelecer um contrato veridictório. "Nesse jogo de persuasão, o enunciador utiliza-se de certos procedimentos argumentativos visando a levar o enunciatário a admitir como certo, como válido o sentido produzido" (FIORIN, 2006, p. 75). Nesse processo de manipulação, que envolve os sujeitos da enunciação, há um contrato que se estabelece entre enunciador e enunciatário, bem como os meios empregados na persuasão do enunciador e na interpretação do enunciatário.

$\mathrm{Na}$ análise apresentada a seguir, é possivel observar mais detalhadamente os processos de manipulação, tanto no nível narrativo quanto no nível discursivo.

\section{OS PROCESSOS DE MANIPULAÇÃo E A MODALIZAÇÃo dOS SUJEITOS}

O encontro entre Ricardo e Raquel, que se dá na entrada de um cemitério abandonado, é resultado do primeiro processo de manipulação que envolve os sujeitos da narrativa. Para que aconteça esse FAZER, no encontro, Ricardo, no papel actancial de destinador-manipulador, busca persuadir Raquel, no papel actancial de destinatário-manipulado, a QUERER ir encontrá-lo. Para tanto, ele age insistentemente com a ex-namorada: "Me implora um último encontro, me atormenta dias seguidos, me faz vir de longe para esta buraqueira, só mais uma vez, só mais uma vez! E para quê? Para ver o pôr-do-sol num cemitério" (TELLES, 2007, p. 30). A manipulação se dá no âmbito da sedução, uma vez que o destinador SABE, conhece o destinatário manipulado, levando-o a FAZER por meio de um juízo positivo sobre sua competência. Raquel, sob pena de renunciar os valores a ela atribuídos, e por estar no controle da relação, por exemplo, realiza o FAZER. Modalizada pelo QUERER-FAZER, Raquel CRÊ ser o sujeito que PODE e SABE, tanto que ao chegar, age de maneira impositiva, reclamando em tom áspero: "Podia ter escolhido um outro lugar, não? - Abrandara a voz. — E o que é isso aî? Um cemitério?” (TELLES, 2007, p. 30). 
Nesse jogo de fazer CRER entre as funções sintáxicas destinador/destinatário, Raquel estabelece com Ricardo uma relação de confiança. Para ela, Ricardo PARECE e É confiável, conforme demonstrado no quadrado semiótico proposto por Greimas e Courtés (2013):

Figura 1 - Quadrado semiótico proposto por Greimas e Courtés (2013)

VERDADE/confiável

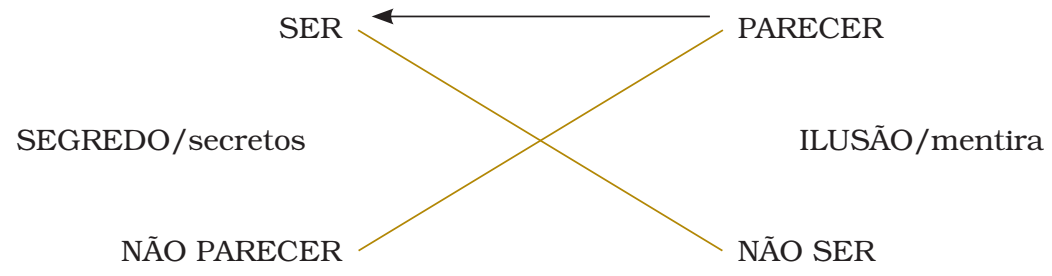

FALSIDADE/falsos

Como reconhecimento pelo FAZER de Raquel, Ricardo lhe oferece a vista de um pôr do sol. Como ela não se interessa pela recompensa oferecida, inicia-se um novo jogo de manipulação e Ricardo, novamente no papel actancial de destinador-manipulador, tenta convencer Raquel, mais uma vez no papel de destinatário-manipulado, a QUERER FAZER, isto é, a QUERER o objeto-valor oferecido, a vista de um pôr do sol dentro do cemitério. O pôr do sol, que era recompensa, passa a objeto-valor, o que resulta num processo de manipulação por tentação, quando o destinador, dotado de um PODER FAZER, manipula o destinatário a QUERER FAZER e receber os objetos-valores a ele oferecidos. A fim de modalizar o destinatário, Ricardo exalta a beleza do pôr do sol e, por meio de um convite, tentar convencer Raquel a entrar no cemitério: "Vamos entrar um instante e te mostrarei o pôr-do-sol mais lindo do mundo" (TELLES, 2007, p. 30). É por meio de um convite, também, que Ricardo tenta estabelecer uma relação de confiança com Raquel: "Vem comigo, pode me dar o braço, não tenha medo" (TELLES, 2007, p. 32). Nesse jogo persuasivo, Raquel transita entre QUERER-FAZER e QUERER NÃO-FAZER, isso porque, mesmo tendo aceitado entrar no cemitério, por várias vezes ela tenta retornar: "Vamos embora, Ricardo, chega. [...] Não gosto de cemitério, já disse. E ainda mais cemitério pobre" (TELLES, 2007, p. 32-33), alterando, dessa maneira, o seu QUERER em relação ao objeto-valor. Nessas ocasiões, Ricardo tenta retomar o contrato outrora estabelecido com Raquel: "Você prometeu dar um fim de tarde a este seu escravo (TELLES, 2007, p. 33). / Raquel, minha querida, não faça isso comigo” (TELLES, 2007, p. 31).

Outro recurso de manipulação utilizado pelo destinador, ao longo do texto, diz respeito ao PARECER. Ricardo muito se esforça em PARECER gentil, delicado e submisso, para tanto, sempre se dirige à Raquel como "minha querida", "meu anjo", isso por repetidas vezes: Minha querida Raquel / Ah, Raquel... / Cemitério abandonado, meu anjo. / Raquel, minha querida, não faça assim comigo. / Estou sem dinheiro, meu anjo, vê se entende. / Mas me lembrei deste lugar 
justamente porque não quero que você se arrisque, meu anjo. / Raquel, Raquel, [...] - Já chegamos, meu anjo. / Pó meu anjo, pó. / Boa noite Raquel. / Boa noite, meu anjo. Também se inserem nesse jogo do PARECER do destinador as atitudes de Ricardo em relação à Raquel, que simula delicadeza: "Brandamente ele a tomou pela cintura (p. 30)/ Acariciou-lhe o braço com as pontas dos dedos (p. 31)/ Delicadamente ele beijou-lhe a mão" (TELLES, 2007, p. 33). O uso dos adjuntos adverbiais de modo brandamente e delicadamente intensificam os sentidos de um destinador que tenta PARECER SER gentil ao seu destinatário. A própria ação, indicada pelo verbo acariciar, encerra esse propósito.

Em síntese, Ricardo é um sujeito que, ao assumir o papel de destinador-manipulador, utiliza-se de diferentes estratégias para convencer Raquel, no papel de destinatário-manipulado, a realizar um FAZER, um último encontro, a vista de um pôr do sol dentro de um cemitério abandonado. Raquel, modalizada pelo QUERER, realiza este FAZER.

Contudo, quando Raquel chega, enfim, à vista do pôr do sol, mais precisamente quando está dentro de um jazigo, a relação de confiança entre destinador e destinatário é rompida. Raquel descobre que a namorada, a qual Ricardo disse ter tido e que insistentemente ele afirmava ter os olhos iguais ao dela, não passava de uma história inventada por ele: "Mas esta não podia ser sua namorada, morreu há mais de cem anos! Seu menti... [...] - Isto nunca foi o jazigo da sua família, seu mentiroso! Brincadeira mais cretina!" (TELLES, 2007, p. 37). Destarte, é a fechadura nova, a qual opunha-se às grades cobertas por uma crosta de ferrugem, que desencadeia um novo fazer interpretativo do destinatário:

Imobilizou-se. Foi erguendo o olhar até a chave que ele balançava pela argola, como um pêndulo. Encarou-o, apertando contra a grade a face sem cor. Esbugalhou os olhos num espasmo e amoleceu o corpo. Foi escorregando. - Não, não... (TELLES, 2007, p. 38).

É nesse momento que entram em jogo o parecer/não parecer da manifestação e o ser/não ser da imanência. Ao perceber que estava presa dentro de uma catacumba, Raquel descobre que Ricardo, apesar de PARECER, NÃO ERA confiável, portanto, um mentiroso. Assim, retomando o quadrado semiótico proposto por Greimas e Courtés (2013), um novo percurso se sustenta:

Figura 2 - Quadrado semiótico proposto por Greimas e Courtés (2013)

\section{VERDADE/confiável}

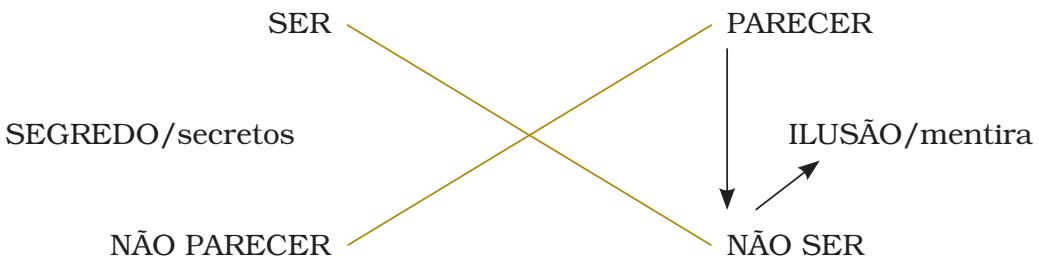

FALSIDADE/falsos

Ao reconhecer Ricardo como mentiroso, outras revelações ligadas ao SER e PARECER, às modalidades veridictórias, são postas em destaques. A primeira delas refere-se à relação de Ricardo e seu objeto-valor. Apesar de Raquel CRER 
que Ricardo queria entrar em conjunção com um último encontro, uma despedida amorosa, na verdade, seu intuito era atraí-la para a morte e, com isso, entrar em conjunção com a vingança. A segunda diz respeito ao objeto-valor, o pôr do sol mais lindo. Reconhecendo Ricardo como mentiroso, o pôr do sol perde a conotação de beleza e assume o valor/sentido de morte. Não era qualquer pôr do sol, mas aquele em que ela só entraria em conjunção quando estivesse presa e a réstia de sol fosse um último sinal de vida.

Nesse jogo de SER e PARECER, Ricardo PARECIA manipular Raquel por sedução e tentação quando, na verdade, suas atitudes encobriam um processo de manipulação por intimidação. Apesar do jogo de PARECER, mostrando-se cordial e submisso, as ações de Ricardo revelam um destinador que, por vezes, pelo contato físico, induzia o destinatário a DEVER fazer:

[...] e ele tomou-a pelo braço. (p. 30) / Brandamente ele a tomou pela cintura (p. 30)/ Ela olhou em redor e puxou o braço que ele apertava. (p. 31) / - Vem comigo, pode me dar o braço, não tenha medo. (p. 32)/ [...] impelindo-a para a frente (TELLES, 2007, p. 34).

Um destinador que, assim como o mato rasteiro que dominava tudo, coloca seu destinatário numa posição de falta de liberdade de escolha. Raquel, mesmo sem perceber, e numa posição de obediência, realiza o FAZER proposto pelo destinador: "Amuada, mas obediente, ela se deixava conduzir como uma criança” (TELLES, 2007, p. 32). Ou ainda, "Ela aconchegou-se mais a ele. [...] Deu-lhe um rápido beijo na face" (TELLES, 2007, p. 34).

\section{ENUNCIADOR E ENUNCIATÁRIO: O FAZER CRER DO ENUNCIADOR}

Assim como ocorre um processo de manipulação entre os sujeitos da narrativa, no nível discursivo existe um FAZER CRER do enunciador ao seu enunciatário. Considerando esse movimento persuasivo entre os sujeitos da enunciação, dois percursos de leitura podem ser reconstruídos. No primeiro deles, o enunciatário é levado a ler o conto na perspectiva de um encontro de despedida entre ex-namorados. O enunciatário que CRÊ nesse percurso, lê o pôr do sol desencadeador de isotopia - como o ápice do encontro, quando os ex-namorados dividirão, juntos, um momento romântico, a vista do pôr do sol. Entretanto, no segundo percurso, revelado mais claramente no final do texto, o pôr do sol remete à morte, uma vez que Raquel só o verá porque estará trancada dentro de um jazigo, na iminência de morrer.

Apesar de as reais intenções de Ricardo serem reveladas ao enunciatário apenas no desfecho do conto, é possivel recobrá-las a partir das pistas deixadas pelo enunciador, as quais, sutilmente, revelam a temática da morte. E, nesse viés de escolhas, a primeira delas tem relação com a enuncividade do discurso. Isto é, o enunciador opta pela enuncividade para recobrir os dois percursos de leitura, projetando no enunciado a terceira pessoa, no tempo então, no espaço do lá: "Ela subiu sem pressa a tortuosa ladeira. À medida que avançava, as casas iam rareando, modestas casas espalhadas sem simetria e ilhadas em terrenos baldios" (TELLES, 2007, p. 29). A debreagem enunciva de pessoa vem figurativizada no pronome "ela" e nas conjugações verbais subiu e avançava, enquanto "a tortuosa ladeira" representa o lá, uma debreagem enunciva de espaço. Assim, a enuncividade de pessoa e espaço reitera a enuncividade de tempo, 
não é o tempo do agora que se enuncia, mas o do então, quando se deram os fatos. Ao projetar um narrador em terceira pessoa, o enunciador opta pelo distanciamento, pela objetividade do discurso. Porém, é justamente no processo de delegação de voz feita pelo narrador ao interlocutor Ricardo - instância enunciativa em que Ricardo assume o eu que fala diretamente ao tu, Raquel -, que evidenciamos as primeiras pistas deixadas pelo enunciador ao enunciatário, acerca do percurso de leitura pautado na temática da morte. Isto é, ao encontrar Raquel, Ricardo afirma: "Juro que eu tinha que ver ainda uma vez toda essa beleza, sentir esse perfume" (TELLES, 2007, p. 30). O uso do adjunto adverbial de tempo, "ainda uma vez", considerando as reais intenções de Ricardo, reforça o sentido de último, de derradeiro, pois, uma vez que ela morra, não haverá outro momento para vê-la, ou mesmo, sentir o seu perfume. Nessa mesma perspectiva, Ricardo diz: "Jamais seu amigo ou amigo do seu amigo saberá que estivemos aqui” (TELLES, 2007, p. 32). Por meio do uso do adjunto adverbial de tempo jamais, podemos ler um Ricardo que planejou, escolheu o local perfeito para largar a ex-namorada trancada, sem que ninguém soubesse e/ou pudesse encontrá-la. Além desses diálogos, quando estão dentro do jazigo Ricardo diz à ex-namorada: “Já chegamos meu anjo, aqui estão meus mortos" (TELLES, 2007, p. 35). Neste caso, o pronome possessivo meus inclui Raquel, ainda viva, entre os mortos de Ricardo. Ou seja, mais uma pista de que ele não a deixaria sair com vida do cemitério. O pronome possessivo aponta, também, para a relação de posse que Ricardo estabelecia com a ex-namorada. Uma vez que ela não se relacionava mais com ele, não sendo mais "propriedade" sua, deveria morrer, não "sendo" de outro; um crime passional, portanto, temática principal da obra.

Nessa mesma linha, de pistas deixadas pelo enunciador ao enunciatário de que o percurso de leitura de morte se revela em vários momentos, podemos destacar a forma como o narrador descreve Ricardo, cujas características destoam de um ex-namorado querendo apenas um encontro de despedida. Descrito pelo narrador como um homem "esguio e magro", com "cabelos crescidos e desalinhados", com "jeito jovial de estudante", vestido com um "blusão azul-marinho", Ricardo revela, pelo sorriso, que não era apenas alguém inocente, mas também malicioso: "Tinha seu sorriso - meio inocente, meio malicioso" (TELLES, 2007, p. 29). Por sinal, a malícia, revelada pelo sorriso, é reiterada mais de uma vez: "Ele riu entre malicioso e ingênuo" (TELLES, 2007, p. 29). É o sorriso de Ricardo que revela, também, um ator que simula encabulamento e esconde a melancolia: "Ele riu também, afetando encabulamento como um menino pilhado em falta. (p. 30)/ Ele tocou na face da imagem recoberta de poeira. Sorriu melancólico" (TELLES, 2007, p. 35). Em suma, por vezes, Ricardo é descrito com características que destoam do percurso de leitura de encontro amoroso, de despedida, de um ex-namorado submisso, inocente, e que quer se encontrar mais uma vez com a ex-namorada. O encabulamento, a malícia e a melancolia, características essas sempre relacionadas ao sorriso, reiteram o percurso de leitura de alguém que simula um encontro amoroso, mas que na verdade prepara uma armadilha para a ex-namorada.

Assim como o sorriso denuncia um Ricardo malicioso, melancólico e encabulado, sua ausência faz transparecer um Ricardo sério, que aparenta ser mais velho e, principalmente, com "rugazinhas" em redor dos olhos, ou melhor, um Ricardo sínico e mentiroso: "Ficou sério. E aos poucos, inúmeras rugazinhas foram-se formando em redor dos seus olhos ligeiramente apertados. Os leques 
de rugas se aprofundaram numa expressão astuta. Não era nesse instante tão jovem como aparentava" (TELLES, 2007, p. 31). Neste contexto, "inúmeras rugazinhas" e "leques de rugas" revelam uma expressão astuta de Ricardo. Esse movimento, entre sorriso que revela e sorriso que desaparece, e por isso mesmo também revela, é posto por duas vezes no texto, o que reitera um enunciador indicando ao enunciatário o percurso de leitura de um Ricardo que finge ser quem não é:

Mas logo sorriu e a rede de rugas desapareceu sem deixar vestigio. Voltou-lhe o ar inexperiente e meio desatento. ( $p .31$ ) / A pequenina rede de rugas voltou a se estender em redor dos seus olhos. A fisionomia, tão aberta e lisa, repentinamente escureceu, envelhecida. Mas logo o sorriso reapareceu e as rugazinhas sumiram (TELLES, 2007, p. 33).

A comprovação deste percurso, de que sorriso encobre o malicioso, acontece quando o ator do enunciado é revelado como mentiroso, na relação entre os sujeitos da narrativa: "Ele já não sorria. Estava sério, os olhos diminuídos. Em redor deles, reapareceram as rugazinhas abertas em leque" (TELLES, 2007, p. 38). Em suma, no viés semântico, as "rugazinhas" apontam para um Ricardo mentiroso, malicioso e muito esperto.

Por fim, aliados às escolhas até aqui relatadas, alguns percursos figurativos, os quais recobrem o sentido de dominação em oposição à inocência, merecem ser destacados nesse jogo de fazer crer.

As figuras do mato rasteiro, erva daninha, musgo e da trepadeira, reiteradas vezes são postas no texto para referir-se a algo que encobre, se alastra e se infiltra por tudo:

No meio da rua sem calçamento, coberta aqui e ali por um mato rasteiro; (p. 29) [...] O mato rasteiro dominava tudo. E não satisfeito de ter-se alastrado furioso pelos canteiros, subira pelas sepulturas, infiltrara-se ávido pelos rachões dos mármores, invadira as alamedas de pedregulhos esverdinhados, como se quisesse com sua violenta força de vida cobrir para sempre os últimos vestígios da morte (TELLES, 2007, p. 32).

Isto é, figuras que recobrem o percurso temático da dominação:

[...] a erva daninha brotando insólita de dentro da fenda, - o musgo já cobriu o nome na pedra. Por cima do musgo ainda virão as raizes, depois as folhas ... (p. 33-34)/ Pararam diante de uma capelinha coberta: de alto a baixo por uma trepadeira selvagem, que a envolvia num furioso abraço de cipós e folhas (TELLES, 2007, p. 35).

Assim como essas figuras recobrem a temática da dominação, outras trazem a temática da inocência para o texto, como a indicação de crianças que brincavam de roda em volta do cemitério: “[...] algumas crianças brincavam de roda. A débil cantiga infantil era a única nota viva na quietude da tarde (p. 29)/ Crianças ao longe brincavam de roda" (TELLES, 2007, p. 39). Nessa relação de dominação e inocência, Ricardo representa a dominação, enquanto Raquel, a inocência, aquela que se deixou dominar. Raquel é o "anjinho de cabeça decepada", a contar pelas vezes que Ricardo a chama de anjo. Um anjo deveras inocente, que acreditou no seu dominador, que ironicamente lhe diz, no último momento em que estiveram juntos: "Boa noite, meu Anjo." (TELLES, 2007, p. 38). 
Enfim, o enunciatário que acreditou que "meu anjo", posto no enunciado, era apenas um jeito carinhoso de Ricardo se dirigir à ex-amada, passa a reconhecer, na enunciação, o sentido de morte para a figura.

\section{CONSIDERAÇões FINAIS}

É possivel, a partir da análise empreendida, pensar em um enunciador que brinca com o enunciatário? Ou as discussões postas no estudo, tratadas como escolhas do enunciador para alertar o enunciatário sobre a ambiguidade do ator, que se mostra e se esconde, seriam deslizes desse mesmo enunciador? Em nosso texto, não tivemos a intenção de responder a essa indagação, posta aqui como uma inquietação necessária, mas para aprofundá-la precisariamos recobrar conceitos que envolvem ethos e pathos, discussão pertinente para um trabalho futuro.

Intentamos, portanto, dar visibilidade, em nosso percurso de análise, que mesmo no discurso enuncivo é possivel recobrarmos as marcas da enunciação. "A debreagem enunciva produz o enunciado enunciado, que é assim chamado para mostrar que mesmo o que parece escapar ao ato enunciativo é enunciado" (FIORIN, 2017, p. 981). Ou ainda, "como exemplo de marcas semânticas da enunciação que se enuncia, podemos citar, na anaforização léxica, a escolha figurativa, que avalia pejorativa ou meliorativamente ideias retomadas, definindo um ponto de vista [...]" (DISCINI, 2003, p. 41).

Quer seja, na manifestação está posto um ator do enunciado desejoso de um encontro de despedida amorosa, enquanto as marcas da enunciação apontam para a imanência, o percurso do pôr do sol enquanto morte. Um ator que planeja, no seu viés, a morte perfeita: "Esta a morte perfeita, nem lembrança, nem saudade, nem o nome sequer. Nem isso" (TELLES, 2007, p. 34).

A guisa de discussão final, é preciso destacar quão bela é a organização do conto como construção literária, cuja temática de crime passional é desenvolvida de maneira tão sutil, até mesmo poética, numa referência ao pôr do sol. Em contrapartida, na vida real, quão triste é a existência desse tipo de crime $^{2}$, ainda tão recorrente em nossa sociedade, em que muitos "Ricardos" acreditam ser, de fato, "donos" de suas companheiras. Uma leitura cara aos alunos, tanto pelo literário, quanto pela temática em pauta. Nesse sentido, o percurso adotado na análise é, também, nossa sugestão de encaminhamento de leitura da obra no contexto escolar.

\section{MANipulation, modalization AND Making Believe in "Venha Ver o PôR do sol"}

Abstract: Through the lights of Semiotics theory, the present paper aims at presenting the study of "Venha ver o pôr do sol", by Lygia Fagundes Telles, evidencing inherent senses from the enunciator's choices. Strategies of discursive manipulation among the narrative subjects, and between the enunciator and the enunciate, as well as the organization of figurative courses and the under-

\footnotetext{
Ver artigo ONU: Taxa de feminicídios no Brasil é quinta maior do mundo; diretrizes nacionais buscam solução. Dados computados em 2016. Disponível em: https://nacoesunidas.org/onu-feminicidio-brasil-quinto-maior-mundo-diretrizes-nacionais-buscamsolucao/. Acesso em: 26 abr. 2019.
} 
lying themes construe part of the analysis. It is also possible to think of a way of working the short story in the school context.

Keywords: Reading. Manipulation. Making believe.

\section{REFERÊNCIAS}

BARROS, D. L. P. Sintaxe narrativa. In: OLIVEIRA, A. C.; LANDOWSKI, E. (ed.). Do inteligivel ao sensivel: em torno da obra de Algirdas Julien Greimas. São Paulo: Educ, 1995. p. 81-97.

BARROS, D. L. P. Teoria semiótica do texto. 4. ed. São Paulo: Ática, 2005. BENVENISTE, É. Problemas de lingüística geral II. São Paulo: Pontes, 1989.

BRASIL. Secretaria de Educação Fundamental. Parâmetros curriculares nacionais: terceiro e quarto ciclos do ensino fundamental: língua portuguesa. Brasília: MEC/SEF, 1998.

BRASIL. Ministério da Educação. Base Nacional Comum Curricular. 2017. Disponivel em: http://basenacionalcomum.mec.gov.br/images/BNCC_EI_EF_110518_ versaofinal_site.pdf. Acesso em: 26 abr. 2019.

DISCINI, N. O estilo nos textos: história em quadrinhos, mídia, literatura. São Paulo: Contexto, 2003.

FIORIN, J. L. Elementos de análise do discurso. 14. ed. São Paulo: Contexto, 2006.

FIORIN, J. L. Em busca do sentido: estudos discursivos. São Paulo: Contexto, 2008.

FIORIN, J. L. Uma teoria da enunciação: Benveniste e Greimas. Gragoatá, Niterói, v. 22, n. 44, p. 970-985, set./dez. 2017.

GREIMAS, A. J.; COURTÉS, J. Dicionário de semiótica. 2. ed. Tradução Alceu Dias Lima et al. São Paulo: Contexto, 2013.

TELlES, L. F. Venha ver o pôr do sol e outros contos. 20. ed. São Paulo: Ática, 2007.

Recebido em 31 de agosto de 2018. Aprovado em 21 de dezembro de 2018. 